\title{
Measurement of the fracture energy in mode I of atmospheric ice accreted on different materials using a blister test
}

\author{
ML.A. Pervier ${ }^{\mathrm{a}}$, D.W. Hammond ${ }^{\mathrm{a}}$ \\ ${ }^{a}$ Cranfield University,Cranfield,MK43 OAL,UK
}

\begin{abstract}
Atmospheric ice is formed when supercooled water droplets strike an object such as a tree, aircraft or wind turbine. Its microstructure and properties vary widely according to the flow and thermal conditions prevailing. The present work was conducted in the Cranfield Icing Wind Tunnel for a european project called STORM (efficient ice protection Systems and simulation Techniques Of ice Release on propulsive systeMs). It aimed at collecting data on the fracture energy of atmospheric ice on four different materials AL2024-T3, Ti-6Al-4V, Platinum and Alexit-411 - using a blister test. This particular test, firstly introduced by Andrews and Lockington [1], have been adapted by Cranfield University to be able to test the ice adhesion in-situ while ice is still accreting on the surface making it closer to real situation. The second part of the paper will focus on the influence of different parameters like the materials ice is accreted on, the total ambient temperature, the tunnel wind speed and the cloud liquid water content which have been investigated over a few icing conditions.
\end{abstract}

Keywords: atmospheric ice, fracture energy, ice adhesion, blister test

\section{Previous work}

Much work is published on atmospheric ice but it is unusual to find data on microstructure, toughness and unambiguous measures of the adhesion of

URL: m.pervier@cranfield.ac.uk (ML.A. Pervier ), d.w.hammond@cranfield.ac.uk (D.W. Hammond ) 


\begin{tabular}{|ll|}
\hline Nomenclature & \\
$a_{g}$ & grains size of ice \\
$\mathrm{c}$ & radius of the flaw \\
$E_{i}$ & Young's modulus of ice \\
$\mathrm{FE}$ & Fracture energy \\
$\mathrm{h}$ & thickness of ice above the flaw \\
$\mathrm{k}$ & shape (or Weibull) parameter of the Weibull distribution \\
$K_{I c}$ & mode I fracture toughness \\
$\bar{m}$ & average value \\
$P_{c}$ & critical pressure needed to remove the ice \\
$\mathrm{T}$ & total temperature of the flow in the tunnel \\
$\mathrm{V}$ & tunnel wind velocity \\
$\mathrm{x}$ & percentage of adhesive fracture \\
$\Gamma$ & gamma function \\
$\theta$ & fracture energy for an adhesive fracture \\
$\lambda$ & scale parameter of the Weibull distribution \\
$\nu$ & Poisson's ratio of ice \\
$\sigma$ & standard deviation \\
$\sigma_{t}$ & tensile strength \\
$2 \tau$ & fracture energy for a cohesive fracture \\
$\mathrm{CIWT}$ & Cranfield Icing Wind Tunnel \\
$\mathrm{LWC}$ & Liquid Water Content \\
$\mathrm{MVD}$ & Median Volume Diameter \\
\hline
\end{tabular}

4 the ice to the body it has formed on. Furthermore, the capabilities of partic5 ular facilities limit the range of flow and thermal conditions under which ice 6 can be made and different studies use widely different techniques to measure 7 the properties of the resulting ice.

8 Atmospheric ice forms due to the rapid freezing of supercooled water droplets 9 when impinging a surface. Its particular formation results in the presence 10 of bubbles of air trapped within the material whose amount depends on the 11 icing conditions and effects on the material properties. With a homologous 12 temperature higher than 0.9 , the mechanical properties of atmospheric ice 13 are highly affected by changing temperature making it an even more chal14 lenging material to study.

15 Fracture energy of atmospheric ice has been rarely reported previously. To 
the authors knowledge only Hammond [2] and Yeong et al. [3] published any values of fracture energy of ice accreted to a substrate. They both used a blister test similar to the one reported here. The process of making ice in Yeong et al.'s experiments was very slow $\left(5 \mathrm{~m} . \mathrm{s}^{-1}\right)$ and only one temperature was tested $\left(-20^{\circ} \mathrm{C}\right)$. The droplets were generated by a spray nozzle using deionised water. Their median volume diameter (MVD) was $20 \mu \mathrm{m}$. The ice was built to a thickness of $10 \mathrm{~mm}$ before the mechanical test was conducted. Each test was repeated three times for statistical purpose. Values between 0.5 and $0.82 \mathrm{~J} . \mathrm{m}^{-2}$ were found for ice accreted on titanium alloy and between

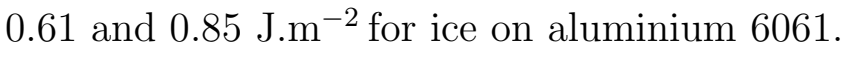

Hammond's experiments were conducted in a running icing tunnel at temperature of $-5,-10$ and $-25^{\circ} \mathrm{C}$ with a cloud liquid water content (LWC) of 0.3 g.m ${ }^{-3}$, a tunnel wind speed of $140 \mathrm{~m} . \mathrm{s}^{-1}$ and a droplet MVD of $20 \mu \mathrm{m}$. The type of fracture has been thoroughly reported and has been found to vary from adhesive to cohesive with decreasing temperature (table 1). The only

\begin{tabular}{|c|c|c|c|c|}
\hline \multicolumn{2}{|c|}{ Temperature $\left(\right.$ in $\left.^{\circ} \mathrm{C}\right)$} & -5 & -10 & -25 \\
\hline Ti-6Al-4V & Fracture energy (J.m $\left.{ }^{-2}\right)$ & 1.3 & 3.9 & $>4.0$ \\
& type of fracture (\% adhesive) & 50 & 0 & 0 \\
\hline Al2024 & Fracture energy (J.m $\left.{ }^{-2}\right)$ & 2.1 & 2.8 & 2.4 \\
polished & type of fracture $(\%$ adhesive) & 80 & 30 & 0 \\
\hline Nickel 99.99\% & Fracture energy (J.m $\left.{ }^{-2}\right)$ & 1.6 & 4.0 & 3.0 \\
ground & type of fracture (\% adhesive) & 100 & 50 & 0 \\
\hline Stainless steel & Fracture energy (J.m $\left.{ }^{-2}\right)$ & 1.6 & 3.4 & 3.0 \\
& type of fracture (\% adhesive) & 80 & 25 & 0 \\
\hline
\end{tabular}

Table 1: Values of fracture energy reported by Hammond [2]

difference between material in term of type of fracture was found with Titanium alloy which had a mix type of fracture even at the highest temperature tested. Looking at the fracture energy values, they have been found to differ largely with temperature and to a less extent with material. Nothing was said about the number of test carried out with each material.

More authors have attempted to measure the tensile strength of atmospheric ice which can be linked to the fracture energy in mode I using the Griffiths criterion. The traditional method to measure the tensile strength, where a sample of the material is elongated until it breaks, is challenging in case of atmospheric ice. The difficulty is to have a good grip on the end of the specimens and to measure the deformation of the sample. 
Druez et al. $[4,5]$ and Tremblay [6] have studied the tensile strength of atmospheric ice in function of ice growth parameters and the test conditions. The ice was accumulated in a cold chamber around a cylinder. This cylinder was made of two parts which were hold together by an internal screw. At the end of the accretion, the screw were removed and the cylinders were only held together by the ice. Each extremities of the cylinders were attached to a traction machine which pulled the ice at a certain strain rate. One hour was needed after the ice accretion to prepare the tensile test. Values between 0.7 and $5 \mathrm{MPa}$ have been obtained for the tensile strength depending on the ice growing conditions and the strain rate. The highest values were obtained at a temperature of $-14^{\circ} \mathrm{C}$ and a $\mathrm{LWC}$ of $1.2 \mathrm{~g} \cdot \mathrm{m}^{-3}$ whereas the lowest values were obtained at temperature close to melting point.

Laforte and Laforte [7] accreted ice on aluminium bars. The ice was made using distilled ionized water and the droplet generated had a MVD of 200 $\mu \mathrm{m}$. After the ice accretion, the specimens were kept at the ice making temperature of $-10^{\circ} \mathrm{C}$ for one hour before the mechanical test was carried out. The iced bars were pulled by a traction machine until the ice breaks off. A strain gauge was glued to the bare side of the aluminium bar to measure the deformation and the strain rate. A load cell was used to measure the tensile force applied to the iced substrate. The tensile strength was calculated from the strain at deicing using a value of $9.9 \mathrm{GPa}$ for the Young's modulus of ice. An assumption was made that the strain on the aluminium bar is the same than the strain at the ice interface. The ice was observed to either detach from the substrate in one piece or to break into several pieces. In the last case, the cracks were perpendicular to the loading direction. Values between 2.8 and $5 \mathrm{MPa}$ were found depending on the ice thickness with the highest value obtained for the thinnest ice deposit.

Mohammed and Farzaneh [8] have also grown ice around a rotating cylinder, however, they had cut an ice sample from the middle of the ice piece. The ice was grown from water sprayed, with a droplet MVD of $40 \mu \mathrm{m}$, a LWC of 2.5 g. $\mathrm{m}^{-3}$ and a temperature of $-10^{\circ} \mathrm{C}$, on an aluminium cylinder rotating at 1 RPM to ensure a uniform ice thickness. A lathe was used to cut the ice to avoid any crack formation. Two cups were attached to the extremities of the ice sample using freezing water and the whole was let to rest for two to three hours. A closed loop electrohydraulic machine was used to pull on the ice specimen. This method gets rid of the influence of the metal, compared to the previous ones, but needs a lot of manipulations (cutting and machining the ice samples, positioning the extensometer, etc.) which could induce pre- 
cracks and lead to inaccurate results. Investigation of the influence of the test temperature, the wind speed and the strain rate were conducted. Strain rate was reported to be the parameter which had the most influence on the tensile strength. The tensile strength obtained was in the range from 0.9 to 1.6 $\mathrm{MPa}$ with the highest value obtained at a test temperature of $-15^{\circ} \mathrm{C}$, a wind speed of $15 \mathrm{~m} . \mathrm{s}^{-1}$ and a strain rate of $5 \times 10^{-5} \mathrm{~s}^{-1}$ (which correspond to the brittle zone where the tensile strength is independent of the strain rate). The traditional tensile test gives satisfactory results but is challenging to use in case of atmospheric ice. Moreover most of the tests were conducted few hours after the ice has been made which could lead to some inaccuracy due to the relax of thermal and internal stresses. The test presented in this paper allows us to measure the fracture energy of atmospheric ice in mode I (and therefore have an idea of the tensile strength) in a running icing tunnel while the ice is still accreting to the substrate.

\section{Methodology}

\subsection{Test principle}

The test rig described in the present paper is based on a blister test first suggested by Andrews and Lockington [1]. It was first modified by Hammond [2] to allow its use in a running icing tunnel and then more recently to produce a more versatile test in terms of substrate material tested and to get a higher number of values for each run. The test consists of a hollow cylinder covered by a thin plastic disc (figure 1). The front surface of the cylinder was placed in the tunnel in a certain way so it was facing the spray of supercooled water. The plastic disc was maintained in position by the use of a vacuum pump which was connected to the back of the cylinder. When a significant thickness of ice, to allow the test to be on plane-strain condition, was accreted on the front surface of the cylinder, pressurized nitrogen was gradually applied on ice through the hole at a rate of $10 \mathrm{bar} / \mathrm{s}$ (which corresponds to a strain rate of $10^{-4} s^{-1}$ ). The pressure needed to break off the ice was recorded by a pressure transducer and was called critical pressure, $P_{c}$. The ice can break off in three different ways: completely adhesive (substrate surface completely free of ice), completely cohesive (fracture propagating through the ice leaving the substrate surface covered by a layer of ice) or mixed which is partly adhesive and partly cohesive (part of the substrate surface was completely free of ice while the other part is still covered by ice). The type of fracture was estimated visually as a percentage of adhesive failure straight after the 


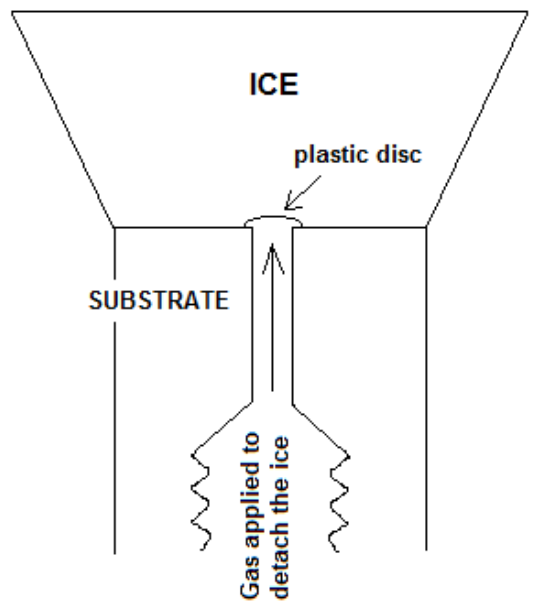

Figure 1: Scheme of the mode I test rig- the cylinder has a diameter of $30 \mathrm{~mm}$, the inner hole of $4 \mathrm{~mm}$ and the plastic disc of $6 \mathrm{~mm}$

ice was detached from the surface. The ice thickness need to be at least 15 $\mathrm{mm}$ to ensure plane strain condition which is a necessary condition in the analytical expressions proposed by Andrews and Lockington [1]. In addition, with an ice thickness of $15 \mathrm{~mm}$ or more, the error in the fracture energy due to a misestimation of ice thickness of $2 \mathrm{~mm}$ would be between 0.01 and 0.02 J.m $\mathrm{m}^{-2}$

The two expressions (equations 1 and 2) established by Andrews and Lockington [1] allow to calculate the fracture energy of ice from the critical pressure measured during the experiments $\left(P_{c}\right)$, the Young's modulus of ice $\left(E_{i}\right)$, the Poisson's ratio of ice $\left(\nu_{i}\right)$, the radius of the flaw $(c)$ and the thickness of ice above the flaw $(h)$. When the type of fracture is cohesive, the fracture energy is noted $2 \tau$ whereas when it is adhesive, the fracture energy is noted $\theta$. Both notations are equivalent and represent the energy needed to create one unit area of new crack while the fracture propagate.

$$
\begin{aligned}
2 \tau & =\frac{P_{c}^{2} c}{E_{i} \times f_{1}} \\
\theta & =\frac{P_{c}^{2} c}{E_{i} \times f_{2}}
\end{aligned}
$$


where $f_{1}$ and $f_{2}$ are

$$
\begin{aligned}
& f_{1}=\frac{1}{1-\nu^{2}}\left(\frac{3}{32}\left[\left(\frac{c}{h}\right)^{3}+\left(\frac{c}{h}\right) \frac{4}{1-\nu}\right]+\frac{1}{\pi}\right)^{-1} \\
& f_{2}=\frac{1}{1-\nu^{2}}\left(\frac{3}{32}\left[\left(\frac{c}{h}\right)^{3}+\left(\frac{c}{h}\right) \frac{4}{1-\nu}\right]+\frac{2}{\pi}\right)^{-1}
\end{aligned}
$$

131

Depending on the type of fracture, cohesive or adhesive, equation 1 or 2 respectively, was used. In case of a mixed type of fracture, the percentage of adhesive fracture, $x$, is visually estimated and the fracture energy, FE, is calculated in the following way

$$
F E=\frac{100-x}{100} \times 2 \tau+\frac{x}{100} \times \theta
$$

The error on the estimation of the percentage of adhesive fracture is $10 \%$ which correspond to an error on the fracture energy of about $0.01 \mathrm{~J} . \mathrm{m}^{-2}$.

The mode I fracture toughness, $K_{I c}$, can be obtained from the fracture energy

$$
K_{I c}=\sqrt{\frac{F E \times E_{i}}{1-\nu^{2}}}
$$

From the fracture toughness, the tensile strength of a bulk of ice can be evaluated from the following equation [9]

$$
\sigma_{t}=\frac{K_{I c}}{\sqrt{\pi a}}
$$

where $\sigma_{t}$ is the tensile strength and $a$ the size of the defect. The largest defect in ice is assumed to be smaller than the grain size. Therefore, the typical size of a defect will be taken as the average grain and the tensile strength equation becomes

$$
\sigma_{t}=\frac{K_{I c}}{\sqrt{\pi a_{g}}}
$$

where $a_{g}$ is the grain size.

The choice of the average grain size as a typical defect size can be surprising as a grain is not a real defect in a material. However, this dimension is relatively easy to obtain from the microstructure and as default of any other flaw dimension known within the material, the value obtained by this way is 
assumed to give a good approximation of the tensile strength.

For all the following calculations, assumptions were made that the Young's modulus and the Poisson's ratio were constant for the whole conditions tested and were taken as $8.5 \mathrm{GPa}$ and 0.31 respectively. Average grains size was measured using the technique described in Pervier et al. [10].

This test has numerous advantages. It has proved to be reasonably reproductible taken into account the brittle properties of ice which can be responsible for large scatter. The plastic disc is initiating the crack meaning that the flaw dimension is known. The pressure rate can be modified so different load rate can be tested. Finally, it allows to measure the adhesion of ice in a running icing tunnel while the ice is still accreting on the front face. This means that thermal stresses due to the heat release during the ice accretion process does not have the time to relax making it closer to real situation of, for example, an aircraft flying in icing conditions or a wind turbine experiencing icing. It is worth to note that the heat released during accretion can be significant and be responsible for the introduction of non negligeable shear stresses at the interface ice/substrate. The influence of the thermal effects on the test results are currently under investigation and are beyond the scope of this paper. Therefore an assumption will be made that the loading in this test is pure mode I.

The dimension of the cylinder is not taken into account in equations 1 and 2. The influence of this dimension has not been studied yet.

\subsection{Description of the test facilities}

Tests were conducted in the Cranfield Icing Wind Tunnel (CIWT). This tunnel is composed of a square test section of $760 \mathrm{~mm}$ in width, a fan driven by an electric motor, a return duct, a heat exchanger and a spray rake. The spray rake consists of 6 rows of nozzles with a total of 99 places for nozzles to allow the user to adapt the cloud. The nozzles bars include one pipe filled by air and within it, one pipe filled by water. By adjusting the pressure of water and air, the droplet size and the LWC of the cloud could be modified. The CIWT has the capability of recreating atmospheric icing condition for supercooled water droplet from 16 to 300 microns at temperature between 0 and $-30^{\circ} \mathrm{C}$ and for tunnel air speed between 30 to $110 \mathrm{~m} \cdot \mathrm{s}^{-1}$.

\subsection{Substrate material and testing conditions}

During the STORM campaign, four reference materials have been selected. The first two are widely used alloys in aerospace and rely on an oxide 
film for their environmental stability. The third one is a noble metal and, therefore, does not contain an oxide layer but has free electrons at its surface. The last one is a polymer, widely used in aerospace, whose stiffness is closer to the stiffness of ice than metal.

- Al2024-T3 unclad and not anodized. Samples were cut from plate of $1.2 \mathrm{~mm}$ in thickness and polish to mirror finish $(\mathrm{Ra}=0.01 \mu \mathrm{m})$

- Ti-6Al-4V. Samples were cut from a plate of $2 \mathrm{~mm}$ thickness and polish to mirror finish $(\mathrm{Ra}=0.01 \mu \mathrm{m})$

- Platinum. Samples of Al2024-T3 were prepared in the same way as described above and were then spluttered with platinum in a sputter reactor. The aluminium surface was cleaned in the sputter chamber in an Argon plasma then an adhesion promoting layer of $\mathrm{Cr}$ of about $5 \mathrm{~nm}$ thickness was deposited on the aluminium surface followed by a platinum layer of about $100 \mathrm{~nm}$ thickness.

- Alexit-411 Clearcoat. This is a reference coating manufactured by Mankiewicz and used by Airbus. Samples were coated on Al2024-T3 coupons slightly polished with carbide paper to obtain a flat and clean surface. The coating thickness was about $100 \mu \mathrm{m}$.

The mirror finish condition has been obtained by the following way. First, the specimens were ground using Silicon Carbide paper starting with 180 grade grit and progressing by steps to 1200 grade grit using water as lubricant. They were then given a thorough rinse and dryed with a soft cellulose based non-woven fabric (3 cycles of cleaning). The polishing was done manually using a Stuers DP plan nylon polishing mat, 3 microns diamond paste and Struers Blue (ethanol based) lubricant. The surfaces were polished three times, each time to a point where the texture from the previous polish was oblitered. The samples were washed as before, three times but using Struers Blue lubricant. They were then lapped using a Struers DP Nap as pad, 1 micron diamond paste and Struers Blue lubricant until no sign remained of the polished finish. The specimens had a mirror finish with some occasional instances of slight scaring from grinding damage in less critical areas of the surface.

Eight icing conditions were chosen to offer a wide range of ice type from glaze to rime (table 2). 


\begin{tabular}{|c|c|c|c|c|}
\hline $\begin{array}{c}\text { Temperature } \\
\left({ }^{\circ} \mathrm{C}\right)\end{array}$ & $\begin{array}{c}\text { Wind speed } \\
\left(\mathrm{m} . \mathrm{s}^{-1}\right)\end{array}$ & $\begin{array}{c}\text { LWC } \\
\left(\mathrm{g} \cdot \mathrm{m}^{-3}\right)\end{array}$ & $\begin{array}{l}\text { MVD } \\
(\mu \mathrm{m})\end{array}$ & Ice type and description \\
\hline-5 & 80 & 1.0 & 20 & glaze - transparent with \\
\hline-10 & 50 & 0.8 & 20 & evidence of runback ice \\
\hline-10 & 80 & 0.8 & 20 & mixed glaze - pretty \\
\hline-5 & 80 & 0.3 & 20 & smooth in aspect with \\
\hline-5 & 50 & 0.3 & 20 & a conical shape \\
\hline-20 & 50 & 0.8 & 20 & $\begin{array}{l}\text { mixed rime - white but } \\
\text { with transparent } \\
\text { aspect. Presence of }\end{array}$ \\
\hline-15 & 80 & 0.3 & 20 & $\begin{array}{l}\text { feathers can be spotted } \\
\text { on side of samples. } \\
\text { Cylindrical in shape. }\end{array}$ \\
\hline-20 & 50 & 0.3 & 20 & $\begin{array}{l}\text { rime - completely } \\
\text { opaque with feathers } \\
\text { on side }\end{array}$ \\
\hline
\end{tabular}

Table 2: Icing conditions and description of the ice obtained

\section{Test procedure}

Before each test, the nozzles were checked to be sure that none of them were blocked. Eight cylinders can be placed in the tunnel at each run. They were positionned on two support bars (figure 2). Each cylinder were spaced from its closest neighbour by $10 \mathrm{~cm}$ (distance between the centre). To ensure a good reproductibility of the mechanical test, the surface of each cylinder was carefully cleaned with ethanol and then dried with a hot air gun. Then the whole test rig was covered. Air was sprayed from the nozzle to make sure all the water remaining in and around the nozzles was sprayed anywhere but on the specimens surface. The specimens were then uncovered and the plastic discs put in place. Finally the tunnel window was closed and the main fan and cooling system were started.

The different parameters were set (LWC, ambient temperature, tunnel air speed, droplet size) and when the temperature in the tunnel was stable, the water was sprayed. Even if an ice thickness of $15 \mathrm{~mm}$ was considered as sufficient, in the majority of runs (only the glaziest conditions would not allow the ice to grow towards the flow but more sidewise. In that case, 15 mm was often seen as the maximum thickness reached before the ice samples 


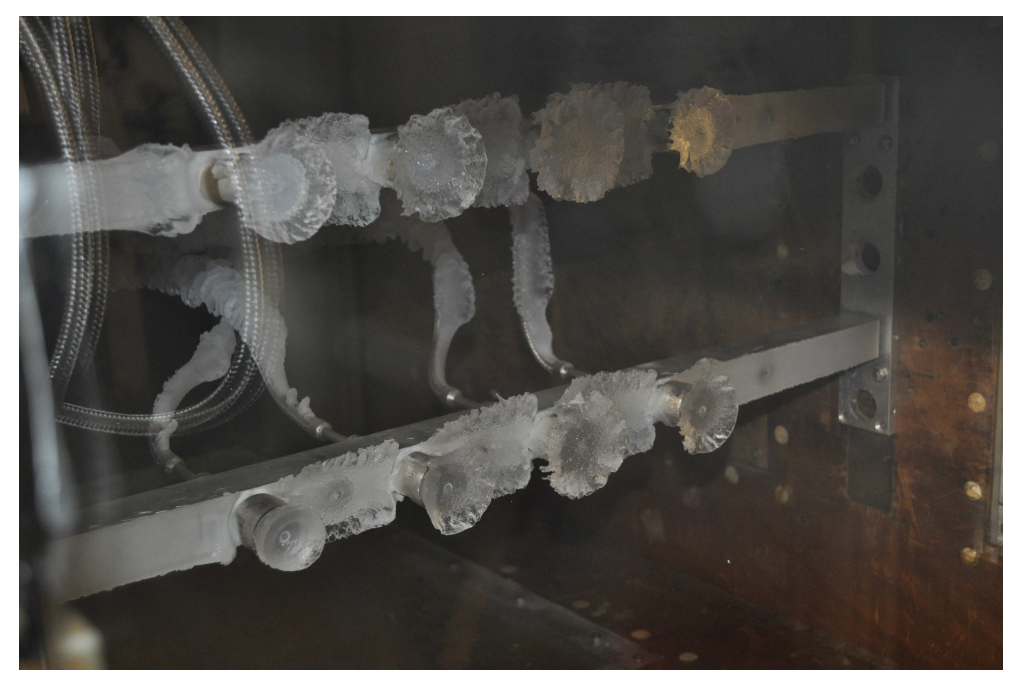

Figure 2: Mode I test rig in place in the test section of the CIWT

started to touched their direct neighbours in the tunnel), the ice was accreted until a thickness of $20 \mathrm{~mm}$ was reached before applying the pressure. With such thickness, the error due to the misestimation of ice thickness of $2 \mathrm{~mm}$ (typical error on the visual estimation of the ice thickness) would be below $0.01 \mathrm{~J} . \mathrm{m}^{-2}$. This is considered as negligible compared to the scatter of the fracture energy values.

The critical pressure needed to detach the ice as well as the mode of fracture and the estimated ice thickness above the flaw were noted. It is worth to note that during the mechanical test (when the pressure is applied to the ice), the tunnel is still running and the ice is still accreting.

Ice is a brittle material, hence, even if care has been taken to have a reproductible test, the results present scatter. It has been found that brittle fracture follow a Weibull distribution [11]. Hence a statistical analysis was carried out using the software Statistica ${ }^{1}$ in order to obtain a mean value and its standard deviation for each conditions. Parameters were chosen in order to obtain the best fit with a threshold of 0 (two parameters Weibull distribution). The Weibull parameter obtained were between 2 and 8. This falls into the family of curve where the probability of ice fracture would be

\footnotetext{
${ }^{1}$ Statistica is a statictics and analytics sofware developped by StatSoft, http://www . statsoft.com
} 
nul at 0 J.m ${ }^{-2}$

\section{Results and discussion}

In all the following, data will be presented in terms of fracture energy and comparison with previous authors will only be made using a trend with different parameters. Runs have been repeated a number of times to obtain around 10 values for each material and each icing condition. In one case ( $\mathrm{T}=-$ $15^{\circ} \mathrm{C}, \mathrm{V}=80 \mathrm{~m} \cdot \mathrm{s}^{-1}, \mathrm{LWC}=0.3 \mathrm{~g} \cdot \mathrm{m}^{-3}, \mathrm{MVD}=20 \mu \mathrm{m}$, Platinum substrate) only 5 values were obtained due to difficulties to remove the ice. An average value, $\bar{m}$, and a standard deviation, $\sigma$, were calculated using a 2 parameters Weibull distribution (equations 7 and 8) where $\lambda$ is the scale parameter, $k$ is the shape (or Weibull) parameter and $\Gamma$ is the gamma function.

$$
\begin{aligned}
\bar{m} & =\lambda \times \Gamma(1+1 / k) \\
\sigma & =\sqrt{\lambda^{2}\left[\Gamma(1+2 / k)-(\Gamma(1+1 / k))^{2}\right]}
\end{aligned}
$$

\subsection{Influence of material}

Comparison of the results obtained for the four reference materials at four different icing conditions is presented on figure 3. The type of fracture is shown in the columns as a percentage of adhesive fracture $(100 \%$ adhesive means fully adhesive and $0 \%$ adhesive means fully cohesive). It is diplayed as the number of test that resulted in a certain type of fracture. Five different categories have been selected to simplify the graph. The colours are lighter as the type of fracture is becoming more cohesive. The crosses represents the average value of the tensile strength and the error bars one standard deviation.

With the two alloy materials, the ice was breaking in a predominantly adhesive way at the highest temperature shown and was gradually becoming cohesive as the temperature was decreased. With the platinum, even at a temperature close to melting point a mixed type of fracture was obtained. Whereas with the Alexit coating, even at low temperature, the ice was breaking predominantly in an adhesive way. Hammond [2] studied the ice adhesion on two different grade of aluminium, Al2024 and Al7075, nickel, titanium alloy (Ti-6Al-4V) and stainless steel. The type of fracture has been thoroughly reported and only little difference has been found between all these materials. As seen on table 1, at the highest temperature tested ice was breaking, from all material except Titanium alloy, in a predominantly adhesive way. Then, 


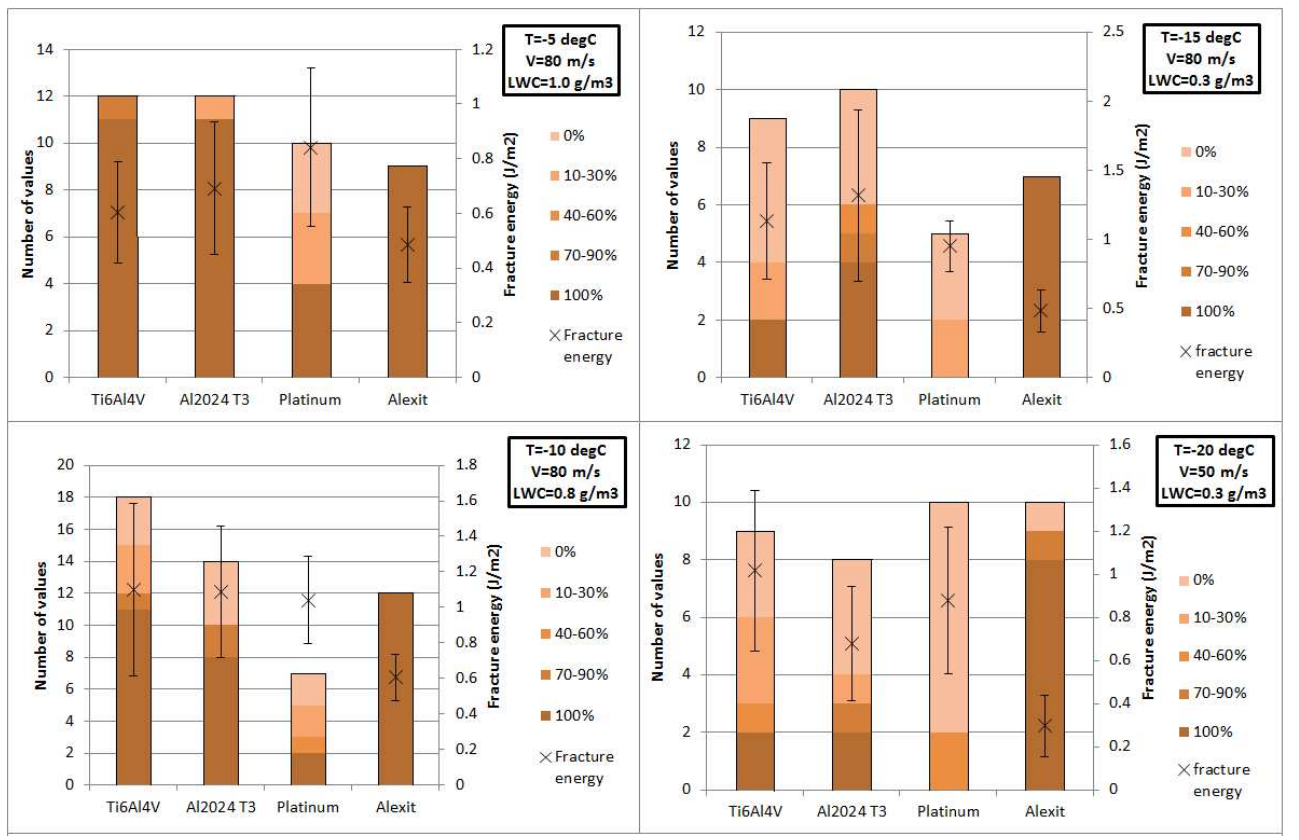

Figure 3: Type of fracture and average fracture energy values for the four reference materials at different icing conditions - the type of fracture is presented as a percentage of adhesive fracture

the fracture type was mixed at $-10^{\circ} \mathrm{C}$ and cohesive at $-25^{\circ} \mathrm{C}$. For Titanium alloy, the fracture type was mixed at $-5^{\circ} \mathrm{C}$ and cohesive at both $-10^{\circ} \mathrm{C}$ and $-25^{\circ} \mathrm{C}$.

Alexit coating is a much softer material than Aluminium alloy, Titanium alloy or Platinum. The standard deviation obtained with this material was narrower than with the other materials. In general, the values obtained with Alexit coating were lower than with the other materials meaning that the ice adhesion was lower than on the other materials tested. On the metallic materials, no clear conclusion could be drawn. In some icing conditions, there was no difference between the three materials whereas in others, one of them presented a slightly higher adhesion. In [2], the fracture energy values reported were lower for Aluminium alloy $\left(2-3 \mathrm{~J} \mathrm{~m}^{-2}\right)$ that for the other materials $\left(3-4 \mathrm{~J} . \mathrm{m}^{-2}\right)$ at temperature lower than $-10^{\circ} \mathrm{C}$. At a temperature of $-5^{\circ} \mathrm{C}$, no difference could be found. Yeong et al. [3] reported values of similar range for aluminium and titanium at $-20^{\circ} \mathrm{C}$. Values for teflon and other hydrophobic and superhydrophobic material were at least 3 times lower. 
Results have been presented on figure 4, sorted by material on which

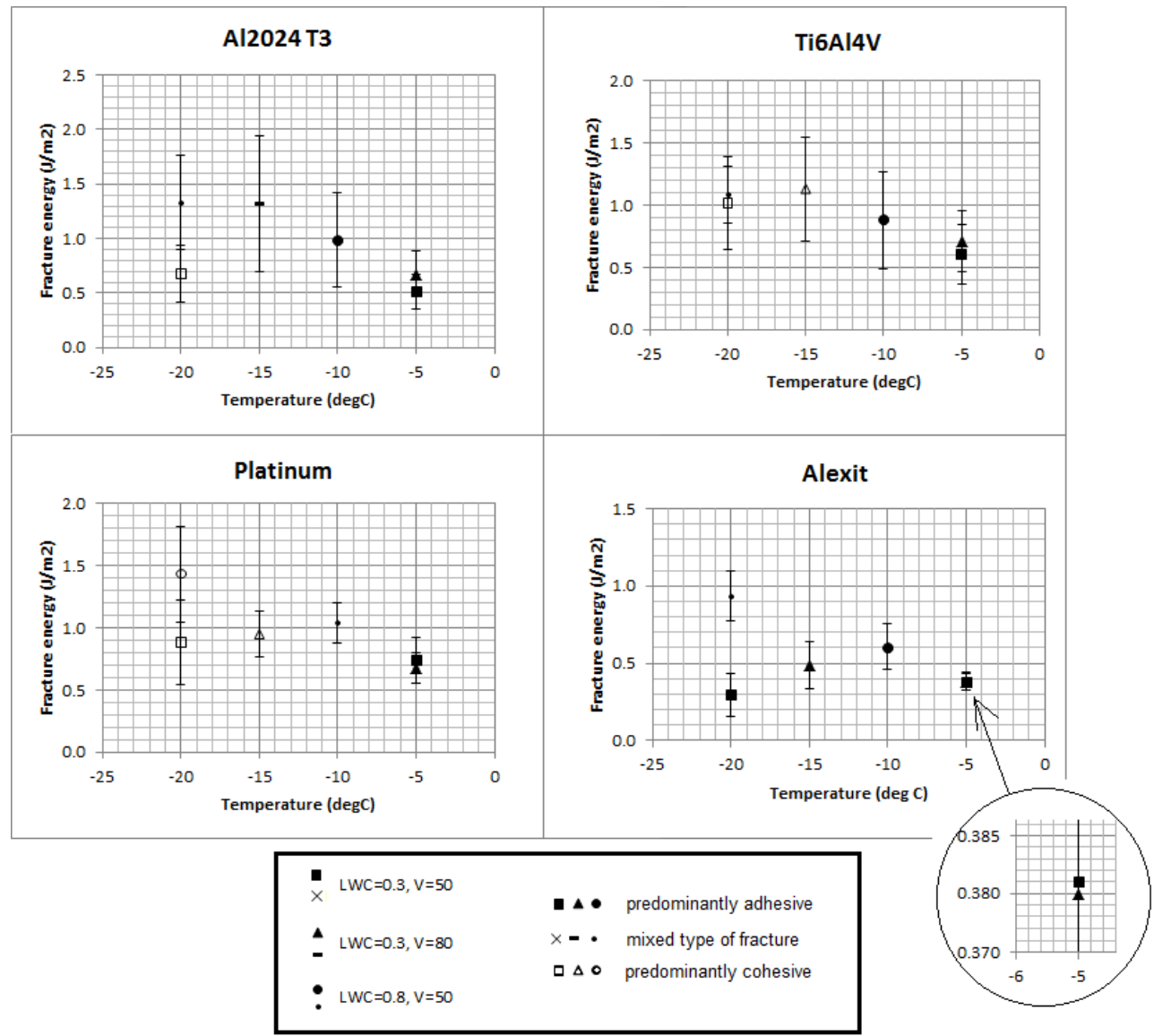

Figure 4: Influence of total ambient temperature on fracture energy of atmospheric ice accreted on each reference material (type of fracture is displayed by different symbol)

ice had been accreted to. They have been sorted in three different series having the same LWC and tunnel wind speed to study the influence of total ambient temperature only. Filled symbols represents fracture predominently adhesive, empty symbols fracture predominantly cohesive and crosses, dashes or points mixed fracture.

Type of fracture, for the metallic substrates, shifted from predominantly adhesive at -5 and $-10{ }^{\circ} \mathrm{C}$ to predominantly cohesive at -15 to $-20{ }^{\circ} \mathrm{C}$. At -10 ${ }^{\circ} \mathrm{C}$ with the Platinum substrate, the type of fracture started to shift to mixed. 
Whereas, for the Alexit coating, the type of fracture was predominantly adhesive in all cases except at a temperature of $-20{ }^{\circ} \mathrm{C}$ with a LWC of 0.8 g. $\mathrm{m}^{-3}$ and a wind speed of $50 \mathrm{~m} . \mathrm{s}^{-1}$. A similar observation, meaning a shift from predominantly adhesive to predominantly cohesive as the temperature was decreased, was reported by Hammond [2] for all the materials he studied. All results except one ( $\mathrm{LWC}=0.3 \mathrm{~g} \cdot \mathrm{m}^{-3}, \mathrm{~V}=50 \mathrm{~m} \cdot \mathrm{s}^{-1}$, Alexit substrate) showed an increase of fracture energy as the temperature decreased. Previous authors have reported either an increase of tensile strength/fracture energy $[2,8]$ or a passage through a maximum between -10 and $-15^{\circ} \mathrm{C}[2,4,5]$.

\subsection{Influence of tunnel wind speed}

Results for the different materials have been presented on figure 5 to illustrate the influence of tunnel wind speed on fracture energy. Two series have been identified where only the tunnel wind speed was varied from 50 to $80 \mathrm{~m} \cdot \mathrm{s}^{-1}$ keeping the total ambient temperature and the LWC constants.

As the temperature was higher than $-10{ }^{\circ} \mathrm{C}$, the tests resulted in ice separation from their substrate in a predominantly adhesive way and therefore no influence of the tunnel wind speed could be observed on the type of fracture. More experiments need to be carried out at lower temperature to have a better understanding on the influence this parameter.

Aluminium alloy and Titanium alloy both presented an increase of fracture energy as the speed was increased. The results obtained with the Alexit coating were totally independent on wind speed. Whereas the Platinum samples presented either no dependence with tunnel wind speed (Temperature of -10 ${ }^{\circ} \mathrm{C}$ and LWC of $0.8 \mathrm{~g} . \mathrm{m}^{-3}$ ) or a decrease of fracture energy as the speed was increased from 50 to $80 \mathrm{~m} \cdot \mathrm{s}^{-1}$ (temperature of $-5{ }^{\circ} \mathrm{C}$ and LWC of 0.3 g. $\left.\mathrm{m}^{-3}\right)$. Druez et al. $[4,5]$ and Mohammed and Farzaneh [8] measured the tensile strength of ice on Aluminium alloy. They reported an increase of tensile strength as the wind speed increased up to $15-16 \mathrm{~m} \cdot \mathrm{s}^{-1}$ followed by a decrease as the wind speed was increased further up to $20 \mathrm{~m} . \mathrm{s}^{-1}$ [8] or 23 $\mathrm{m} . \mathrm{s}^{-1}[4,5]$.

\subsection{Influence of cloud liquid water content}

Two series had been identified to illustrate the influence of cloud LWC for the four reference materials (figure 6). The same system of symbols have been used to represent the type of fracture as in 4.2 .

For the Aluminium alloy, the type of fracture did not seem to depend on the 
LWC. The type of fracture was predominantly adhesive for the series at $-5^{\circ} \mathrm{C}$ and predominantly cohesive for the series at $-20^{\circ} \mathrm{C}$. With the Titanium alloy substrate, at a temperature of $-5^{\circ} \mathrm{C}$, the type of fracture remained predominantly adhesive as the LWC was varied from 0.3 g. $\mathrm{m}^{-3}$ to 1.0 g.m ${ }^{-3}$. At a temperature of $-20^{\circ} \mathrm{C}$, the type of fracture changed from predominantly cohesive at a LWC of $0.3 \mathrm{~g} . \mathrm{m}^{-3}$ to mixed at a LWC of $0.8 \mathrm{~g} . \mathrm{m}^{-3}$. For the Platinum at a temperature of $-5^{\circ} \mathrm{C}$, the type of fracture changed from predominantly adhesive at a LWC of 0.3 g.m ${ }^{-3}$ to mixed at a LWC of 1 g.m $\mathrm{m}^{-3}$ while, at a temperature of $-20^{\circ} \mathrm{C}$, it remained predominantly cohesive at both LWC tested. For the Alexit coating, at a temperature of $-20^{\circ} \mathrm{C}$, the type of fracture shifted from predominently adhesive at a LWC of $0.3 \mathrm{~g} . \mathrm{m}^{-3}$ to mixed at a LWC of 0.8 g.m $\mathrm{m}^{-3}$. At a temperature of $-5^{\circ} \mathrm{C}$, the type of fracture was identical for both LWC tested. Various scenarios seemed to happen with the different material and there is no obvious trend with the icing conditions tested.

Regarding the fracture energy, for the Titanium alloy and the Platinum substrates, results seemed relatively independent of LWC. For the Aluminium alloy, at a temperature of $-5^{\circ} \mathrm{C}$ and a wind speed of $80 \mathrm{~m} \cdot \mathrm{s}^{-1}$, no change in the fracture energy could be observed as the LWC was increased from 0.3 to $1 \mathrm{~g} . \mathrm{m}^{-3}$. On the other hand, at a temperature of $-20^{\circ} \mathrm{C}$ and a wind speed of $50 \mathrm{~m} . \mathrm{s}^{-1}$, the fracture energy almost doubled as the LWC was increased from 0.3 to $0.8 \mathrm{~g} \cdot \mathrm{m}^{-3}$. For the Alexit coating, both series presented an increase of fracture energy as the LWC was increased but to a much larger extent at $-20^{\circ} \mathrm{C}$ and $50 \mathrm{~m} \cdot \mathrm{s}^{-1}$. Druez et al. [5] measured the tensile strength of ice on aluminium at two different LWC $\left(0.8\right.$ and 1.2 g.m $\left.{ }^{-3}\right)$. They reported higher tensile strength values at the highest LWC.

\section{Conclusion}

A blister test has been successfully used to measure the fracture energy of ice in a running icing tunnel. Four reference materials have been studied under a range of icing conditions and the influence of each parameter has been investigated. In general, results were consistent with previous authors especially concerning the metallic alloys.

A coating Alexit-411 with a thickness of approximately $100 \mu \mathrm{m}$ has been found to reduce sensibly the ice adhesion compared to the metallic substrates. The most influencing parameter was the ambient temperature for which the fracture energy was higher at lower temperature. With the metal- 
lic substrate, the type of fracture was also affected; a shift from adhesive fracture to cohesive fracture was observed as the temperature decreased.

\section{Acknowledgement}

The research leading to these results has received funding from the European Union seventh framework programme (FP7/2007-2013) under Grant Agreement no.605180.

\section{References}

[1] Andrews E.H. and Lockington N.A. (1983) The cohesive and adhesive strength of ice. Journal of Materials Science, 18:1455-1465, doi:10.1007/BF01111965

[2] Hammond D.W. (1996) Microstructure and mechanical properties of some small impact ice accretions. 7th international workshop on atmospheric icing of structures

[3] Yeong Y.H., Milionis A., Loth E., Sokhey J. and Lambourne A. (2015) Atmospheric ice adhesion on water-repellent coatings: wetting and surface topology effects. Langmuir, 31:13107-13116, doi:10.1021/acs.langmuir.5b02725

[4] Druez J., Cloutier J. and Claveau L. (1987) Etude comparative de la résistance à la traction et à la compression de la glace atmosphérique. Journal de physique, colloque C1, tome 48:337-343

[5] Druez J., Laforte J.L. and Tremblay C. (1989) Experimental results on the tensile strength of atmospheric ice. Proc. 8th intn. conference offshore, mechanics and arctic engineering, 4:405-410

[6] Tremblay C. (1991) Détermination de la résistance à la traction de la glace atmosphérique. Master's thesis

[7] Laforte C. and Laforte J.L. (2009) Tensile, torsional and bending strain at the adhesive rupture of and iced substrate. Proc. of the 28th international conference on ocean, offshore and arctic engineering OMAE2009-79458 
[8] Mohammed A.M.A. and Farzaneh M. (2011) An experimental study on the tensile properties of atmospheric ice. Cold regions science and technology, 68:91-98, doi:10.1016/j.coldregions.2011.06.012

[9] Tada H., Paris P.C. and Irwin G. (2000) The stress analysis of cracks handbook. p.40-42. ASME, doi:10.1115/1.801535

[10] Pervier ML.A., Pervier H., Hammond D.W. (2017) Observation of microstructures of atmospheric ice using a new replica technique. Cold Region Science and Technology, 140:54-57, doi:10.1016/j.coldregions.2017.05.002

[11] Jayatilaka A. (1979) Fracture of engineering brittle materials. Applied science publishers, London 


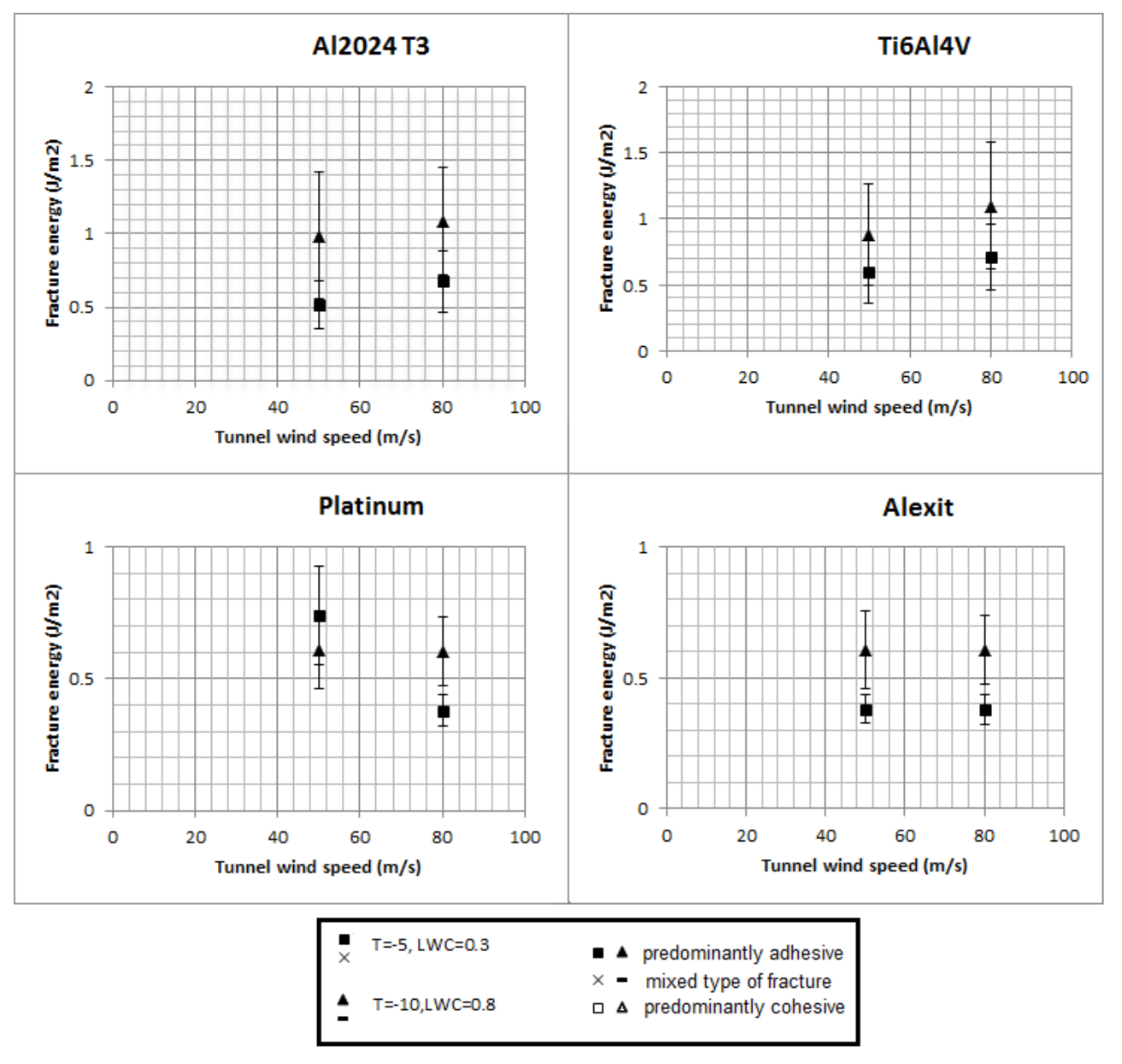

Figure 5: Influence of tunnel wind speed on fracture energy of atmospheric ice accreted on each reference material 


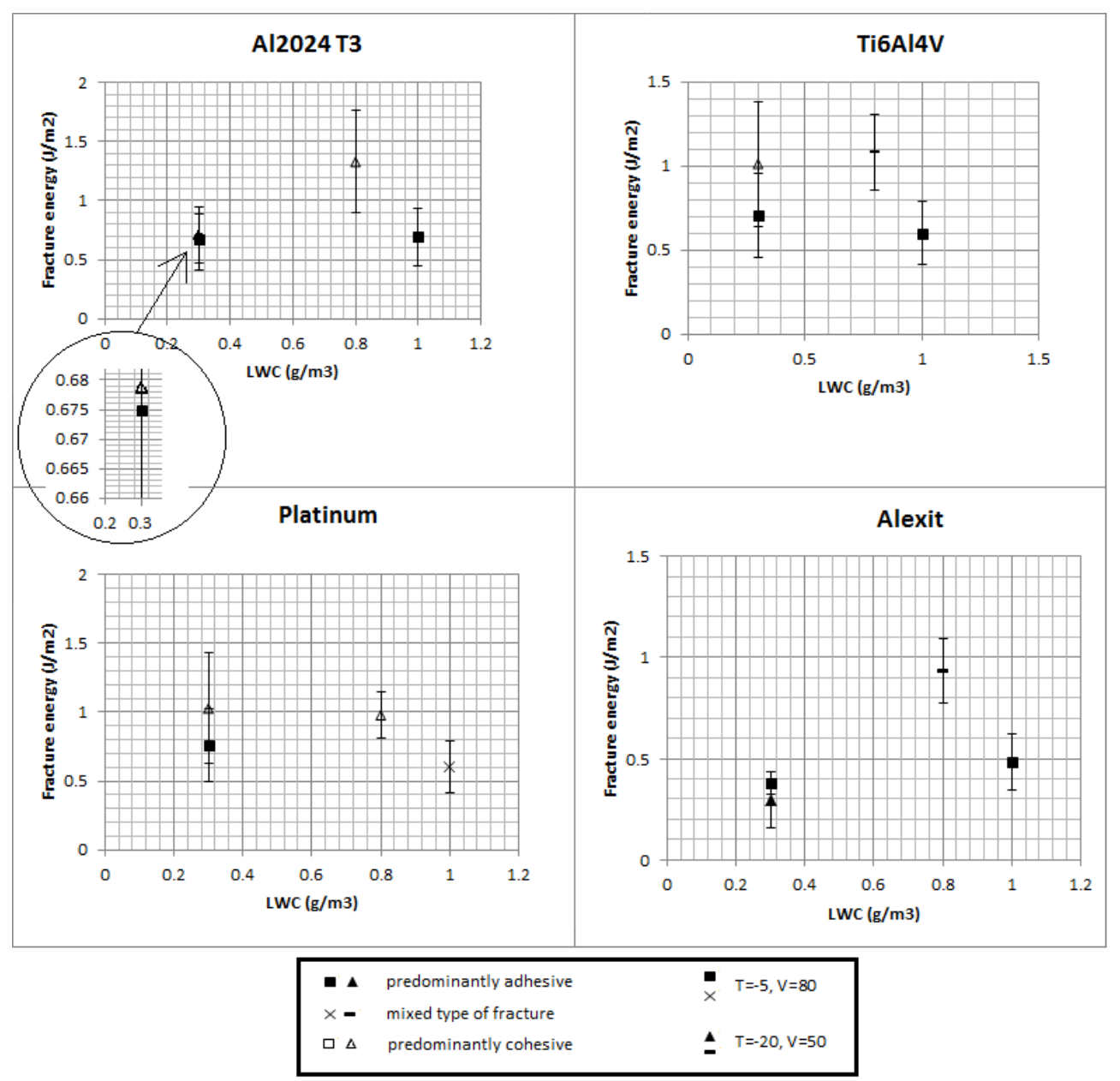

Figure 6: Influence of LWC on fracture energy of atmospheric ice accreted on each reference material 


\title{
Measurement of the fracture energy in mode I of atmospheric ice accreted on different materials using a blister test
}

\author{
Pervier, Marie L. A.
}

Elsevier

Pervier MA, Hammond DW. Measurement of the fracture energy in mode I of atmospheric ice accreted on different materials using a blister test, Engineering Fracture Mechanics, Volume 214, June 2019, pp. 223-232

https://doi.org/10.1016/j.engfracmech.2019.02.003

Downloaded from Cranfield Library Services E-Repository 